\title{
Frustraciones imperiales en la franja del Caribe occidental: Robert Hodgson y el Virreinato del Nuevo Reino de Granada a finales siglo XVIII
}

Imperial Frustrations in the Western Caribbean Stretch: Robert Hodgson and The Nuevo Reino de Granada Viceroyalty at the End of the $18^{\text {th }}$ Century

DOI: https://doi.org/IO.22380/20274688.2050

Recibido: 23 de junio del 2021

Aprobado: 30 de julio del 2021
ANTONINO VIDAL ORTEGA**

Centro de Estudios Caribeños de la Pontificia Universidad Católica Madre y Maestra de República Dominicana antoninovidal@pucmm.edu.do

RAÚL ROMÁN ROMERO***

Universidad Nacional de Colombia, sede Caribe rromanr@unal.edu.co

* This article is part of the project "Connected Worlds: The Caribbean, Origin of Modern World". This project has received funding from the European Union's Horizon 2020 research and innovation programme under the Marie Sklodowska Curie grant agreement No 823846. Directed by Consuelo Naranjo Orovio del Instituto de Historia-CSIC.

** Doctor en Historia de la Universidad de Sevilla (España), ha sido conferencista y ponente en diversos eventos académicos nacionales e internacionales. Entre sus publicaciones más recientes se encuentran: Desde otros Caribe. Fronteras poéticas e identidades (202I), en colaboración con Margaret Shrimptom Masson; Memorias, historias y olvidos. Colonialismo, sociedad y politica en San Andrés y Providencia (2019), en colaboración con Raúl Román R.; y “Los inicios de la ciencia en el Caribe neogranadino: Pedro López de León, teoría y práctica en la cirugía de la Cartagena del siglo Xvir”, en Historia Crítica (2019), en colaboración con Jairo Alonso Solano. Orcid.org/0000-0002-0012-325X

*** Doctor en Historia de América, magíster en Estudios del Caribe e historiador. Desde el año 2014 es presidente de la Asociación Colombiana de Estudios del Caribe (Acolec), y desde el 2010 es líder del grupo de investigación Nación, Región y Relaciones Internacionales en el Caribe y América Latina. Tiene como una de sus líneas de trabajo Regiones Fronterizas, Puertos y Hombres de Mar 


\section{R E S U M E N}

El presente artículo analiza las dinámicas sociales y políticas que se produjeron en el contexto de las disputas imperiales entre ingleses y españoles en las costas de la Mosquitia y los territorios adyacentes, ubicados en el Caribe occidental, a finales del siglo xviII. Se analiza cómo a pesar de los planes ingleses de tomar el control del río San Juan para establecer una ruta entre el Caribe y el Pacífico centroamericano, estos fracasaron por los intereses disímiles y las tensiones entre los militares de la armada inglesa y las autoridades de Jamaica. En estas tensiones se destacó el militar inglés Robert Hodgson, quien desempeñó un papel importante, primero como parte de la armada inglesa y luego como prisionero y negociador con los españoles. Además, se examina el rol de la inteligencia militar de los marinos españoles y la actuación del Virreinato del Nuevo Reino de Granada, liderado por el virrey Caballero y Góngora, con miras a frustrar cualquier proyecto inglés sobre Centroamérica.

Palabras clave: Caribe, franjas imperiales, Caribe occidental, Robert Hodgson, Mosquitia, Pacífico, Virreinato del Nuevo Reino de Granada.

\section{$\begin{array}{llllllll}A & B & S & T & R & A & C & T\end{array}$}

This article analyzes the social and political dynamics that emerged in the context of imperial disputes between English and Spaniards in Mosquitia coasts, and in the adjacent territories located by the West Caribbean Coast at the end of $18^{\text {th }}$ century. It is analyzed how regardless the plans English had to take control over San Juan River to establish a route between Central American Caribbean and Pacific coasts, they failed due to dissimilar interests and to the tensions between English army militaries and Jamaican authorities. In these tensions it is found the English military Robert Hodgson, who played an important role, first, as part of the English army and later as a prisoner and negotiator with the Spaniards. In addition, it is examined the role that Spanish marine's military intelligence played and also the actions led by Viceroy Caballero y Góngora, with his purpose to frustrate any English project over Central American.

Keywords: Caribbean, imperial stretches, Western Caribbean, Robert Hodgson, Mosquitia, Pacific, Virreinato del Nuevo Reino de Granada

en el Caribe. Entre sus publicaciones más recientes se encuentran: Los paises centroamericanos y Colombia. Historia, relaciones y desencuentros en el Gran Caribe (2020), en colaboración con David Díaz Arias, y “De vasallos británicos a súbditos españoles. Los márgenes borrosos de los imperios en el Caribe occidental a finales del siglo XVIII y principios del siglo XIX”, en Temas Americanistas, n. ${ }^{\circ}$ 40, (2018), en colaboración con Antonino Vidal. Orcid.org/0000-0002-3186-5168 


\section{Introducción}

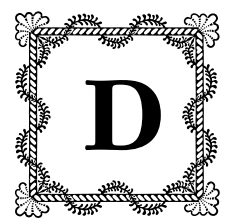

urante el siglo XviII, el mar Caribe aumentó su condición de centro de operaciones navales de los imperios europeos. El incremento del comercio directo con Europa hizo que los apostaderos navales adquiriesen una relevancia mayor en la defensa del territorio. En el caso de España, el apostadero de Cartagena de Indias, en el Caribe suroccidental, tuvo bajo su responsabilidad proteger la Mosquitia, el Darién y la costa de la Guajira, donde británicos, holandeses calvinistas y sefarditas practicaron desde el siglo xvir la extracción de maderas nobles y tintóreas, pieles de animales, bálsamos y carey. Los apostaderos eran bases navales que bajo su jurisdicción tenían extensas áreas con el fin de salvaguardar los dominios reales, rechazar intromisiones comerciales, defender los situados y evitar asentamientos enemigos (Solano 79-IO5). A Cartagena le tocó resguardar el istmo de Panamá, que poseía la condición estratégica de entrada al Pacífico, pues la Gobernación de Jamaica tenía fácil acceso e interés en los litorales de la Mosquitia y Yucatán (Bernardini y Fiering; Klooster 58-73; Rupert 9I-I26; Hunt I-IO; Solórzano II-22; Elliot; Valencia; Román y Vidal).

Las costas centroamericanas del Caribe fueron una zona periférica desde la Conquista, un territorio marcado por la interacción multiétnica con una dinámica relación con el medio ambiente y conectado al ancho mundo atlántico (García, "Hibridación" 44I-462; Paquette 187-2I4). Tras dos siglos de interacción en sus litorales, las poblaciones mixtas surgidas quedaron en un estado ambiguo, sin jurisdicción clara ni sujeción absoluta a los imperios (Fuentes, El sujeto). Su población fue descrita como una clase de zambos compuesta de pocos indios puros, de algunos blancos y mulatos forajidos, y de mestizos de negros e indianos, considerados gente sin Dios ni ley (García "Hibridación”, 44I-462; Prado 318-333; Gould 764-786; Vidal y Román I6I-I78).

Fabricio Prado sostiene que en estas poblaciones el mestizaje y la importancia de las identidades étnicas, religiosas y regionales, además de complejos procesos de etnogénesis, fueron centrales, y que entre ellas la manipulación de las leyes estuvo por encima, incluso, de las jurisdicciones políticas (Santana y Sánchez 695-712; García, "Hibridación”; Offen, “The Sambo" 319-372; Fuentes, El sujeto). La Mosquitia fue una frontera imperial en la cual la interacción social dio paso a negociaciones, incluso de estatus racial, pues a lo largo del tiempo colonial el avance europeo reconfiguró las identidades, propiciando la 
aparición de pactos y negociaciones de todo tipo (bargaining power). Al negociar, resistiendo selectivamente al colonialismo, las sociedades originarias reconfiguraron sus identidades políticas, religiosas y corporativas (Bosch; Muñoz; Cervera; Shrimptom).

El siglo XVIII fue clave en la conformación de los espacios caribeños, tiempo en el que no solo se dieron guerras que alteraron el actuar de los imperios, sino que se produjeron fracasos y derrotas de toda índole. España evidenció lo complejo del control de sus posiciones frente a una Inglaterra en expansión colonial y financiera. En I776, los ingleses sufrieron la independencia de las trece colonias, que, además de aliviar a los españoles, los obligó a un replanteamiento sobre sus estrategias para un ejercicio colonial más efectivo (Millette).

De ese proceso resultaron enfrentamientos y negociaciones en las que se redistribuyeron los territorios. Dado que el litoral caribe centroamericano era estratégico para las hegemonías, fue objeto de estrategias militares y diplomáticas continuadas. Se trató de un espacio en los contornos que requirió exploraciones y sagaces negociaciones entre espańoles, ingleses y nativos para consolidar dominios (Floyd; Fuentes, Rutas).

Este trabajo centra su atención en el papel desempeñado por el marino inglés Robert Hodgson, quien, como otros hombres de mar y marinos ilustrados en los bordes de los dominios imperiales, sobrevivió gracias a su capacidad de negociación, en ocasiones por encima de su nacionalidad y de la lealtad a su rey. Los hombres de mar como él tuvieron un papel histórico extraordinario como actores en las periferias imperiales (Corvisier; Marchena y Cuño). Analizamos la actuación de Hodgson desde I782, cuando fue capturado y sostuvo, durante cinco años, una negociación, a veces ambigua y compleja, con el virrey Caballero y Góngora, quien después de la paz de París de 1783 evidenció el interés del Virreinato del Nuevo Reino de Granada en el Caribe suroccidental (Román y Vidal 23-43). El proceder de Hodgson como marino de rango, de gran conocimiento militar y astucia política, permite observar un proceso de confrontación entre imperios, no desde la óptica del combate, sino desde las estrategias de la inteligencia militar y la negociación política, en medio de un complejo entramado de intereses donde Hodgson, al igual que los pueblos nativos de la franja mosquita, quedaron insertos en las disputas imperiales. Sostenemos que en esta franja imperial del Caribe se desarrollaron dinámicas que exigieron manejos flexibles por parte de los centros de poder, que conllevaron situaciones excepcionales en la dirección de los asuntos políticos y económicos y en las 
negociaciones con estos individuos y, con ello, a frenar o frustrar los proyectos del adversario en la administración de los asuntos imperiales ${ }^{\mathrm{I}}$.

La investigación utiliza como fuente principal el expediente titulado " $\mathrm{Si}$ tuación de la Costa de los Mosquitos 1783 y 1787”, que recoge el caso de Robert Hodgson. Es un documento administrativo voluminoso, que contiene la negociación, casi por un lustro, en el escenario de Jamaica, Portobello, Bluesfield, Matina, San Andrés y Providencia, el Darién y Cartagena de Indias. El texto proporciona una visión privilegiada de las fisuras entre los militares ingleses y los intereses del Virreinato del Nuevo Reino de Granada en estos territorios. La documentación reposa en la Secretaría de Guerra del Archivo General de Simancas (AGs). Esta información es complementada con el informe Economía de la Nueva Granada y pacificación de la Mosquitia, del virrey Caballero y Góngora, que recoge su preocupación por el Caribe occidental, documento ubicado en la Sección Diverso del Archivo Histórico Nacional de Madrid (Aнnм). La Biblioteca Virtual de Defensa en España también ha tributado a esta investigación por la riqueza de su colección de mapas y planos, que permitieron aproximaciones a la región en su conjunto.

Para dar un orden al artículo, en la primera parte se examinan las disputas imperiales, pero también los antecedentes de las negociaciones de paz entre Inglaterra y España antes y después de 1783; en la segunda parte, se analizan las hostilidades y los intentos de los ingleses de tomar el control de Nicaragua para establecer una ruta de conexión entre el Caribe y el Pacífico, así como los fracasos de estos esfuerzos por parte de los ingleses desde Jamaica y la frustración del plan del coronel Robert Hodgson. La tercera parte revisa las circunstancias del arresto de Robert Hodgson y el proceso de negociación que inició con el Virreinato del Nuevo Reino de Granada; la cuarta parte explora los acuerdos en el largo proceso de negociación y el plan de Hodgson para que España tomara el control estratégico de la zona. La quinta parte revisa el cumplimiento de los acuerdos de las partes negociadoras y los intereses del Virreinato del Nuevo Reino de Granada por el espacio del Caribe occidental, hasta el sometimiento de Hodgson al rey. Finalmente, se presentan en forma de conclusiones unas

I El tema de los márgenes y el ejercicio de dominación suscitó una gran discusión, al ser definidos como espacios dentro de la influencia estatal con dinámicas propias, en los que se instauran formas alternativas de lo político y lo económico, y donde además convergen formas paralelas de justicia y comprensiones particulares de la soberanía (Dass y Poole; Appadurai; Bernabeu). 
consideraciones generales en torno a la situación vivida en esta disputada franja imperial del espacio caribe.

\section{Los establecimientos británicos en la costa de la Mosquitia 1740-1759}

En 1730 los establecimientos ingleses se extendían desde Black River hasta cabo Gracias a Dios y eran auxiliados desde Jamaica. Los distintos habitantes de la Mosquitia, a pesar de las conexiones y la influencia inglesa, mantenían sus costumbres y viejas creencias religiosas. La Gaceta de Guatemala sostenía que "estos colonos tenían marina que recorría el mar de las Antillas y poseían comercio libre exterior, armas y todo cuanto necesitaban” (Gámez 90-9I). Los zambos mosquitos y los ingleses establecieron un beneficioso negocio de trata: los zambos secuestraban indígenas del valle de Matina e incluso en la región de Talamanca, que vendían en Jamaica. Desde 1679, España, ante la imposición inglesa, les reconoció a algunos colonos el permiso de mantener sus hogares, basándose en la idea del derecho adquirido que legitimaba su presencia, recogido en el tratado de Sevilla de 1730 (Offen, "British”; Gámez 17-87).

Con la guerra de la Oreja de Jenkins, en I739, los ingleses urdieron planes navales con los que pretendían apoderarse de Nicaragua. Para ello, enviaron agentes con el fin de asegurar la cooperación zambo-mosquita. Aunque el gobernador de Yucatán atacó a los pobladores y destruyó sus establecimientos, en 1740 Edward Trelawney, gobernador de Jamaica, informaba que había un centenar de ingleses que incitaban a los zambos contra los españoles. Ese mismo año, el almirante Handyse, al mando de una flota, intentó tomar El Realejo en el Pacífico (Gámez 94).

En 1740, Trelawney comisionó al capitán Hodgson, quien convocó a los líderes mosquitos, los invitó a hacerse súbditos de Inglaterra y les otorgó el nombramiento de almirantes y generales. La estrategia funcionó y ganaron la amistad de los mosquitos, que iniciaron sus hostigamientos contra los españoles. En respuesta, en 174I el Virreinato de Nueva España ordenó al ingeniero Luis Díez la fortificación de Matina (Gámez 93). En 1744 se trasladaron colonos ingleses, quienes organizaron un gobierno civil y construyeron fortalezas en Black River y Roatán, controlando así la bahía de Honduras; de esta forma, quedó establecida la Superintendencia. El patrocinador del capitán Hodgson en esta empresa fue William Pitt, mariscal de campo dependiente de Jamaica, 
antiguo poblador e influyente comerciante que dirigía Black River y mantenía negocios madereros desde esta zona hasta el Wallix (Belice), ubicado entre el golfo de Honduras, y la península de Yucatán. En calidad de superintendente, Hodgson levantó poblaciones, instaló jueces y agentes del orden, fomentó la agricultura y el comercio y estrechó la amistad con zambos e indígenas, a los cuales permitió usar su justicia tradicional (Griffith 677-706).

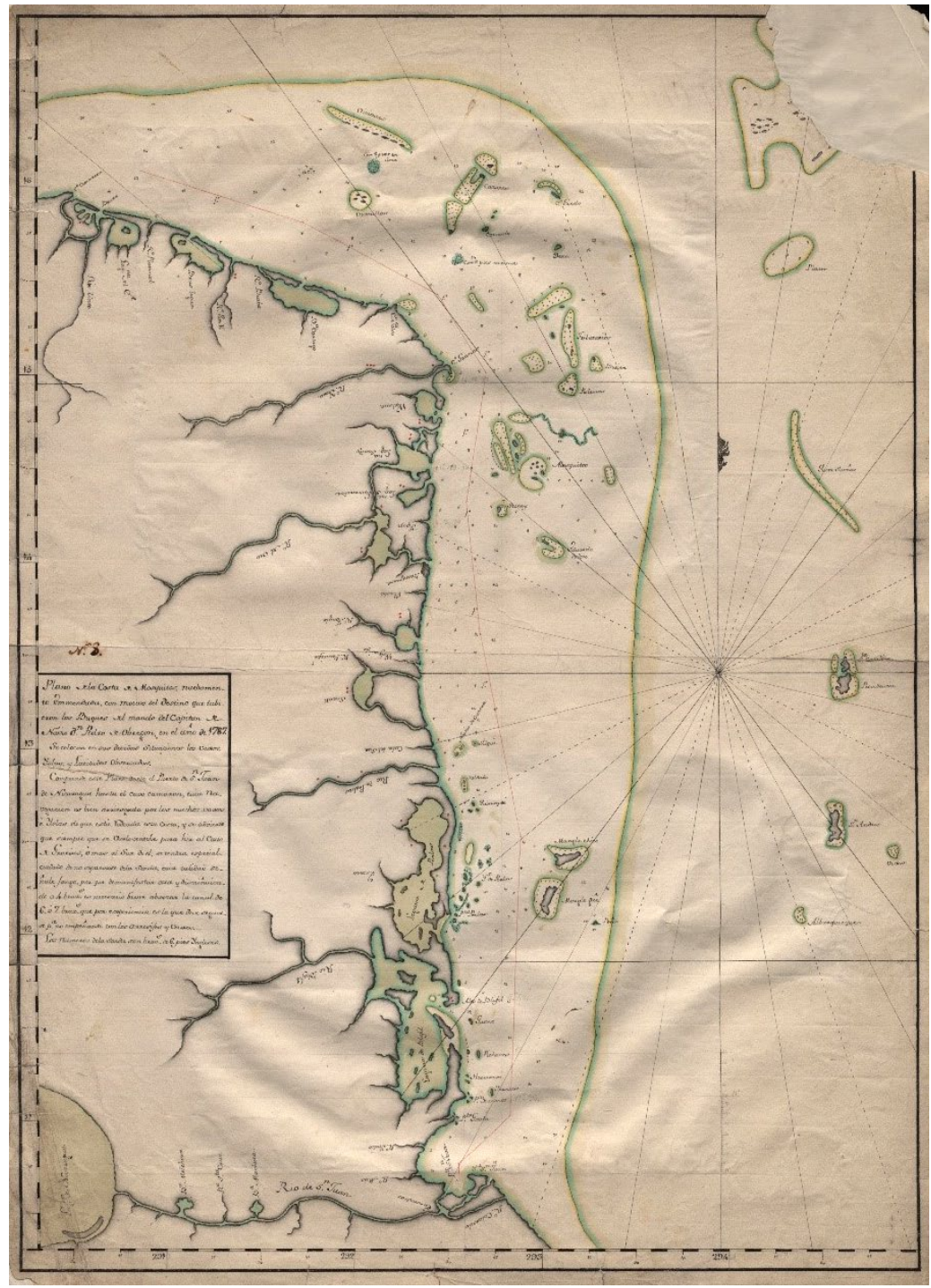

$\rightarrow$ FIGURA I.

Plano de la costa de Mosquitos

Fuente: BVDE, MPCN, I2-B-6, I787. 
En 1748, con la Paz de Aquisgrán, los españoles retomaron el río San Juan y se reorganizaron. Hodgson justificó su presencia para controlar a los mosquitos y para ello fue nombrado coronel. Los incumplimientos de los acuerdos por la parte inglesa llevaron al marqués de la Ensenada a dictar un plan de expulsión desde el golfo de México hasta la costa de la Mosquitia. En 1759 murió el capitán Hodgson padre, su sucesor, Otway, mantuvo continuidad en lo político, sin embargo, en 1762 hubo otra expedición por el río San Juan que fracasó, dejando una estela de hostilidades que disminuyeron en 1763 con los acuerdos de Fontainebleau en el contexto de la Paz de París (Gámez IO2). En 1778, tras la alianza con Francia, con el Decreto del Libre Comercio se dio un giro brusco en lo económico y lo político. Los ingleses pasaron a la ofensiva y centraron nuevamente su objetivo en Nicaragua, que ofrecía la vía de comunicación interoceánica.

\section{El controvertido Robert Hodgson hijo y los planes de la ruta interoceánica 1767-1783}

Tras la muerte del capitán Hodgson, su hijo Robert Hodgson heredó parte de su influencia y reconocimiento entre los habitantes de estas costas y ello le facilitó una actuación política, económica y militar de importancia. Con el tratado de París de 1763 se estipuló que Gran Bretaña destruiría sus fortificaciones en la costa norte de Honduras, por esta razón, en 1767 el presidente de la Audiencia de Guatemala, Pedro Salazar y Herrera, contrató a Hodgson temporalmente al servicio de España para llevar a cabo esa tarea (Gámez IO2).

Concluida su misión, Hodgson regresó a Irlanda, desde donde fue requerido en Londres para conferirle el grado de capitán de ingenieros y, confidencialmente, de superintendente y comandante general de la Mosquitia, con la misión de recuperar Nicaragua y Guatemala. Para distraer a los españoles de su objetivo, Hodgson se centró en los derechos fiscales, que redujo al $2 \%$ en efectivo, y expidió certificaciones de deuda de exportación, asunto que causó malestar entre los colonos, acostumbrados a las políticas de Jamaica.

Hodgson aprovechó las relaciones de su progenitor para instalarse, pero, al no depender de Jamaica sino de Londres, generó desconfianza a las autoridades jamaicanas al imponer, en I768, un gobierno independiente bajo su supervisión. Nadie había ostentado tanto poder político en esas costas. Su desempeño fue una interminable batalla contra los colonos y perdió el favor jamaicano. James Lawrie, líder de los colonos, lo acusó de acaparar tierras, de comerciar con los 
españoles, de extender su influencia a las islas aledañas y de mantener una camaradería con los mosquitos, debido, entre otras razones, al esplendor del ron (Shuman 156-179). Además de su salario, Hodgson obtuvo una cantidad secreta de 3000 pesos anuales para estudiar la topografía de la costa y elaborar mapas precisos e informes para la Corte (Gámez I05; Dickinson). En I769, sin consultar, Hodgson, en un temerario y ambicioso proyecto, lanzó una expedición militar a Bluesfield, con el objetivo de apoderarse del valle de San Juan, pero fracasó y fue destituido de la Superintendencia por violar las estipulaciones del Tratado de 1763 (Gámez Io6).

A pesar de las dificultades políticas que le trajo la temeraria acción a Rober Hodgson, el comercio creció: tortugas, zarzaparrilla, bálsamos, pieles, caoba y palos tintóreos, por calidad y demanda, eran vendidos a Curazao. En ello incidió también el nuevo estatus de los asentamientos madereros en Yucatán y Black River, que demandaban carne y equinos. Entre tanto, los misioneros católicos denunciaban que los mosquitos incursionaban en Costa Rica, Talamanca y Panamá, mientras que los gobernadores de Nicaragua y Costa Rica iniciaron la guerra contra estos. Hodgson intervino en Matina para apaciguarlos. Entre I776 y I780, la costa norte centroamericana estaba poblada por 150 blancos, en tanto que otros 300 vivían en Sandy Bay. Entre todos tendrían a su disposición unos 4500 esclavizados, entre ellos Ioo indígenas y cerca de ro ooo mosquitos zambos (Gámez iıi; Offen, "The Sambo" 35-65; Reichert, "El contrabando”).

Hodgson fue nuevamente acusado de comerciar con españoles, lo que desató desavenencias con los comerciantes que denunciaban sus tratos con Cartagena de Indias. La persistencia de los enfrentamientos hizo que Jamaica enviase una comisión de investigación que responsabilizó a Hodgson de la inestabilidad política. En 1775, el canciller Lord Darmauth proyectó un nuevo régimen administrativo en consenso con Jamaica, pero 1776 estuvo plagado de dificultades: de un lado, la independencia de las trece colonias, y de otro, una revuelta de esclavizados (Reichert, "El contrabando" 3; Vidal y Román).

Del lado español también se tomaron algunas medidas para preservar y controlar mejor estas costas: desde Cartagena de Indias y La Habana se organizaron expediciones navales para estudiar litorales e islas y levantar una cartografía más precisa (Ortega del Cerro; Puig; González-Ripoll). De las nuevas políticas resultó un impulso misional y el diseño de un osado plan de poblamientos. Asimismo, se negociaron alianzas con los jefes mosquitos desde el cabo Gracias a Dios hacia el sur, lo que no siempre se dio de manera exitosa (Reichert, Sobre las olas 3; Román y Vidal). 
Tras la muerte de Pitt, suegro de Hodgson hijo, los ingleses carecieron de gobierno formal y se disgregaron en dispersas explotaciones forestales con sus esclavizados, particularmente en Sandy Bay, Black River y la isla de San Andrés, lugares desde los cuales exportaron maderas a Jamaica a cambio de mercancías inglesas, con las que alimentaban la amistad de los mosquitos. En Inglaterra se calculaba el valor anual de este comercio en $\mathrm{I} 30$ ooo libras anuales, con recaudo fiscal de 5000 libras anuales, sin contar la exportación clandestina. A ello se agregarían cientos de barriles de azúcar y grandes cantidades de madera de caoba, añil, plata, copela y oro en pocas cantidades, y sumadas grandes partidas de caballos y mulas, además de mucho contrabando para evitar el fisco (figura 2).

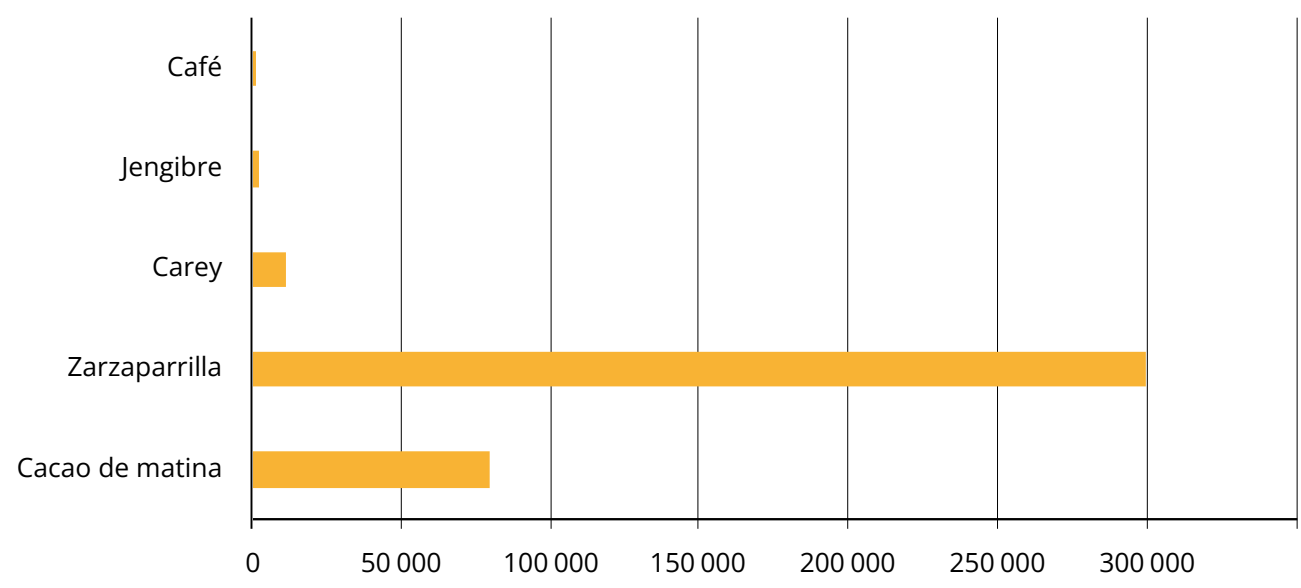

a FIGURA 2.

Productos y cantidad en libras, $\mathbf{1 7 7 6}$

Fuente: Gámez III.

En octubre de 1777 Hodgson presentó en Londres su proyecto para tomar Nicaragua, argumentando que si contaba con medios tendría éxito. Finalmente, obtuvo respaldo, pero dos inconvenientes truncaron su empresa, de un lado, en 1778 el jefe Alpairez, gobernador de Laguna de Perlas, negoció con Cartagena de Indias un acuerdo de paz que les permitía a los mosquitos mantener sus haciendas, ganados y comercio libre. Del otro, en 1779 estalló otra guerra entre España e Inglaterra. A final del año Hodgson partió de Inglaterra como comandante en jefe de la expedición, con un navío de guerra y varios transportes, más tres regimientos a su disposición. Tomó rumbo a Nicaragua, pero al llegar a Jamaica supo que Jhon Dalling, el gobernador, había despachado una expedición antes de su llegada (Gámez II7). Las hostilidades navales se intensificaron 
en todo el Caribe y la amenaza del ataque francoespañol a Jamaica arruinó su plan (Gámez I34-I35).

En marzo de 1780, la expedición asaltó el río San Juan con siete buques de guerra y cincuenta piraguas de indios zambos. Dos meses llevó tomar El Castillo, pero la disentería ocasionó una desastrosa derrota, con cuatro mil muertos y cuantiosas pérdidas. Mientras tanto, en el Pacífico, el almirante Jhonson no pudo tomar El Realejo, y a pesar de la presión a Hodgson para que lo apoyara, este, resentido con Dalling, no intervino. Finalmente, en 1783 la Paz de París y el adicional firmado en 1786 permitieron conservar para Inglaterra la zona de la caoba en Honduras (Conover).

\section{La captura de Hodgson y la nueva visión sobre el Caribe occidental para España}

Pese a su frustrado plan, las operaciones de Hodgson en esta zona continuaron, y a comienzos de 1783 el gobernador de Panamá informaba del incidente de una goletilla con correspondencia para el apostadero de Cartagena de Indias, que fue apresada por una balandra inglesa frente a Portobelo. Tras el asalto, sus tripulantes fueron echados en un bote que fue a parar a Palenque, un pequeño puerto distante de Portobelo a doce leguas. Una vez rescatados se supo que el corsario inglés secuestró al patrón del barco y a tres mujeres que viajaban en este. La acción ofendió el honor de los militares, quienes aprestaron el jabeque El Santo Cristo, que con veinte hombres inició la persecución. Al amanecer, unas diez leguas al norte, cambió la suerte y el jabeque encontró un paquebote inglés que tras un enfrentamiento depuso las armas (AGS, $S G U, 6945$, I, f. 98).

Para sorpresa, el paquebote Sally transportaba a Robert Hodgson, coronel de Inglaterra encargado de Nicaragua, quien, con precauciones militares, fue conducido a la casa del alcalde ordinario Lázaro María de Herrera, que lo alojó con respeto a su grado (AGS, $S G U, 6945$, I, ff. I62-I63). Después, comenzó un interrogatorio en el que Hodgson ofreció información de su derrotero. A cambio, acordó que sus hombres fuesen intercambiados por prisioneros españoles en Jamaica.

En el interrogatorio declaró que el mes de agosto anterior, con motivo de la retoma española de Black River, había zarpado de Jamaica con una escuadra formada por diez fragatas y tropas con destino a Gracias a Dios. Al llegar, habían comprobado que sus defensores, la mayoría enfermos, claudicaban sin 
resistencia, capitulando como prisioneros de guerra que debían ser llevados a Trujillo para liberarlos "de los rigores y crueldades de los indios que los trataban de pasar a cuchillo”. En total, en Riotinto se habían entregado como prisioneros 742 hombres y veinticuatro oficiales. El coronel Hodgson cumplió el acuerdo y los envió a Trujillo y Omoa.

Hodgson declaró que "quedó en aquellos destinos en asuntos precisos de su Corte" hasta recibir órdenes que lo obligaban a replegarse a Port Royal como tercer jefe en la cadena de mando, ante la inminencia de un ataque francoespañol. El 24 de diciembre había embarcado desde Bluesfield. Así mismo, declaró que a bordo viajaban la viuda de un comerciante de Jamaica, la esposa del capitán y sus dos hijos, el secretario del coronel, dos negros criados y cuatro indios, entre ellos una mujer, todos empleados suyos (AGS, $S G U, 6945$, I, ff. 99-100).

Por "vía reservada", el gobernador de Panamá expuso la intención inglesa de establecerse "en el cabo de Gracias a Dios y todo el río Tinto", lo cual generó alarma, por tener un puerto en "la mar del sur para sus armadas". En el momento, los ingleses quedaron en la costa en espera de refuerzos, que según el coronel "se irán multiplicando con la llegada de tropas desde Jamaica y Europa con mucha artillería”, para desarrollar sus ideas. Dejaba entrever el malestar que existía entre ingleses y zambos mosquitos por el maltrato infligido a uno de ellos por parte de un oficial británico, suceso que motivó discordia y desavenencias entre los aliados.

El premio fue la documentación incautada, que por extrañas circunstancias Hodgson no tiró al mar. La información provocó un giro inesperado en el último cuarto del siglo XviII para el enfrentamiento entre ambas monarquías en el Caribe occidental. Entre lo confiscado había un libro con observaciones de las costas de Guatemala, Mosquitos, Nueva España e incluso Buenos Aires; correspondencia con la Secretaría de Estado para América; otro libro, dividido en cuatro partes, que describía los actos del Consejo, las representaciones de los pueblos mosquitos y borradores de cartas a jefes ingleses, entre ellos a Jhon Dalling, gobernador de Jamaica, opositor y enemigo político de Hodgson. La tercera carpeta contenía mapas de la provincia de Nicaragua y croquis e informes de la costa, ríos y lago de Nicaragua (AGI, Guatemala, MP, 333 al 342; Guatemala, MP, 333, Arquitectura militar). También diarios de navegación, testimonios de prisioneros, convenios de abastos de tropas e, incluso, impresos del Parlamento inglés. Además, cartas reservadas de militares y comerciantes de Jamaica, que incluían reflexiones propias y permisos para establecer negocios en la Mosquitia (AGS, $S G U, 6945$, I, ff. I8I-I84). Dado el valor de la información, el gobernador 
envió a Hodgson a Cartagena de Indias e informó al virrey Caballero y Góngora, por la dignidad del prisionero y el alcance del plan urdido por el enemigo.

\section{El virrey Caballero y Góngora: un estratega de primer orden}

Tras ser informado, el virrey advirtió el alcance de lo acontecido, y de inmediato sospechó que el arribo de Hodgson a Panamá no había sido casual. La correspondencia reservada, el sistemático trabajo cartográfico y las detalladas descripciones de las costumbres de sus habitantes, que no destruyó en el momento de su captura, le hacían sospechar de sus intenciones. De inmediato, abrió comunicación con los mandos de Cartagena para informarse. Todos los que mantuvieron contacto con el inglés confesaron "que tenía un talento e instrucción nada común" y confirmaron el valor de lo incautado (AGS, $S G U$, 6945 , I, f. I85).

El virrey comunicó el caso a Madrid, pues era asunto de competencia ministerial. La situación, totalmente prioritaria, fue manejada por el ministerio y ejecutada por el virrey (AGS, $S G U, 6945$, ff. 220-230). A comienzos de marzo de I783 se dispuso el traslado de Hodgson a Santafé de Bogotá, la fría y distante capital del virreinato. Como prioridad, la documentación incautada debía enviarse en el primer champán disponible (AGS, $S G U, 6945$, I, ff. I86-I90).

Con destino a Jamaica, capitaneado por Manuel de Vargas, se aprestó un flag of truce $e^{2}$ con los prisioneros ingleses para canjearlos por un buque capturado, cargado de tabaco, que fue enviado desde La Habana a Cartagena para surtir el estanco. La carta del gobernador tuvo una respuesta desairada de Archibald Campbell, gobernador de Jamaica, quien reemplazó a John Dalling tras su derrota, que según Vargas llevaba "el orgullo de su nación con muy poca cultura y sin ninguna consideración”, pues, a pesar del esmero del gobernador Roque Quiroga, en el envío de los prisioneros Campbell calumnió hasta a "los hombres de su buque apresado" (AGS, $S G U, 6945$, I, f. 239).

Campbell contestó que el tabaco del bergantín que iba de Cuba a Portobelo había sido vendido y gran parte exportado, pero que, entendiendo que en Kingston quedaba alguno, consintió que se vendiera a los cartageneros, 
no sin antes aclarar que ninguna embarcación apresada por navío de guerra y remitida a Port Royal, conforme a leyes británicas, podía ser rescatada. Solo "la inclinación a la humanidad de este asunto puede inducir en algún modo a consentir dicha solicitud", y aceptó el canje de los quince prisioneros. Finalmente, Vargas obtuvo la liberación del coronel Juliá, apresado en Black River con sus hombres meses atrás, aunque Campbell sugirió que, tras la paz de 1783 , Hodgson debía ser liberado.

Una semana después, la goleta entró en Cartagena con el tabaco y los quince soldados canjeados, lo cual confirmaba que la paz entre ambas naciones estaba publicada (AGS, $S G U, 6945$, I, f. 242). A mitad de abril, Hodgson propuso un trato al virrey, solicitando su libertad, superadas las "asperezas de la guerra". Ofreció el juramento de vasallaje y su fidelidad y la de los pueblos mosquitos con posteridad. A cambio, solicitaba mantenerse en Nicaragua, pues, afectado por la entrada en vigor de la paz, que obligaba a los ingleses a abandonar la costa y las islas aledañas, sus negocios se hacían ilícitos. Como prueba, dio su palabra de honor de "que no tomaría las armas contra los españoles" (AGS, SGU, 6945, I, ff. 325-333). Solicitó permiso para tomar una embarcación neutral que partiera de Cartagena, justificándose en que su familia "estaba expuesta en el mar" (AGs, $S G U, 6945$, I, f. 253).

\section{La inteligencia militar española se pone en marcha. Traductores y gacetas}

Caballero y Góngora activó la inteligencia militar y solicitó a los gobernadores del litoral caribe poner "empeño especial en vigilar todo lo inglés". Hecha pública la paz, mantener a Hodgson prisionero atentaba contra el honor militar. La impaciencia del inglés y la generosa propuesta precipitaron su partida hacia Jamaica.

A pesar de los preparativos de su traslado a Bogotá, el virrey canceló el plan en el que pretendía, como manifestó por vía reservada, "ampliar con mańosidad para asegurarme de los designios de los ingleses en los dominios de SM", usó todos los recursos a su disposición y apostó a la "inteligencia y celo del administrador de Correos en Cartagena, José de Fuertes, que como práctico en la lengua inglesa procurase introducirse con el citado Hodgson aparentando amistad para aprovechar en lo que fuese posible" y desvelar el modo en que los ingleses pensaban las costas de Nicaragua. Adicionalmente, por la disposición de Hodgson, buscaba 
conseguir un acuerdo que verificase el cumplimiento de la paz y que los mosquitos aceptasen el dominio español (AGS, $S G U, 6945$, I, ff. 30I-305). En septiembre llegó a Cartagena una carta de Campbell dirigida al virrey, en la que mostraba complacencia, expresaba respeto e informaba del arribo del coronel Hodgson a Jamaica (AGS, $S G U, 6945$, I, f. 309).

El ingeniero Antonio Narváez, gobernador de Riohacha y Santa Marta, al tanto de los acontecimientos, tuvo el "esmero y la vigilancia de indagar" y remitir toda información acerca de los ingleses y del comercio sefardita holandés que abundaba en las costas de Santa Marta, y a mediados de mayo envió una carta acompañada de las gacetas de Jamaica y Ámsterdam, que confirmaba el plan de Nicaragua y ratificaba lo revelado por Hodgson (AGS, $S G U, 6945$, I, ff. 305-306). La gaceta describía las tensiones y rivalidades por la toma de América Central y concluía que la avaricia, y "no el amor a la gloria”, había guiado al oficial Dalyrimple, quien, respaldado por el gobernador de Jamaica, Jhon Dalling, se había adelantado a Hodgson para tomar Nicaragua, con un balance desastroso (AGS, $S G U, 6945$, I, ff. 345-354). Al margen de no considerar las epidemias y de la falta de comunicación con los mosquitos, logró tomar Omoa, recuperar las islas y organizar una entrada hasta el lago de Nicaragua, sin embargo, sus omisiones, el desconocimiento de la zona y la precipitación, le permitieron al capitán general de Guatemala, Matías Gálvez, recuperar la costa en 1783 (Pastor).

\section{El proyecto inglés de tomar Nicaragua para llegar al mar del sur}

José Fuertes, traductor de los documentos, debía procurar adquirir noticias relativas "al establecimiento que la nación inglesa" tenía en la Mosquitia, y aprovechar la experiencia de Hodgson, que la habitaba desde 1764, cuando, como capitán de infantería y con carácter de superintendente, empezó a convivir con sus habitantes. Las conversaciones entre Fuertes y Hodgson durante el cautiverio los vincularon más allá del deber, y Hodgson manifestó que su corte proyectaba tomar Nicaragua y, una vez protegido el sur, apoderarse de Guatemala. El informe de Fuertes recogió sus impresiones sobre el marino subrayando que era "un hombre algo material, pero muy hábil, muy general y cuyos principios anunciaban haber estado más tiempo en las peligrosas costas de la América que en el gran mundo de Londres". 
Conocía las costumbres y el comercio de sus habitantes, las corrientes, los bajos, los fondeaderos y las dificultades de la costa hasta el Atrato, detallando la climatología y las características del río San Juan y el lago de Nicaragua. Del mismo modo, expuso los motivos para quedarse en la costa con sus negocios y los recursos que poseía; afirmaba que "sus conocimientos, singularmente sobre todo del golfo de Honduras y la provincia de Nicaragua son muy vastos e interiores, nada ignora de sus producciones, giro, tráfico y circunstancias del terreno" (AGs, $S G U, 6945$, I, ff. 315-320).

Hodgson había conocido la región en las expediciones de su padre y su suegro, antes de hacer carrera militar en Inglaterra. Después, a partir de I763, reconoció como ingeniero la costa desde Portobelo hasta Honduras, fijando los límites de las explotaciones madereras (Offen, "British Logwood" II3-I35) ${ }^{3}$. Por último, durante nueve años fue superintendente de la costa de los Mosquitos, tiempo en el que conoció el interior del "país" y observó sus fuerzas, sondeó ríos y lagos, midió caminos y conoció el carácter de sus gentes y el clima, lo que lo llevó a manifestar en Londres la facilidad de abrirse paso en tiempo de guerra desde el Caribe al Pacífico (AHnm, sD, Colecciones, 32, n. ${ }^{\circ}$ 36, ff. I-72).

Hodgson, en tanto que fracasaba Dalling en su expedición, permanecía en Jamaica sin intervenir. Viajó a Londres en I78I y mostró los yerros cometidos por los expedicionarios. Regresó con patente de coronel para intentar, una vez más, tomar Nicaragua, que, como reflexionaba Caballero y Góngora, si hubiese tenido "éxito habría impedido el comercio de los españoles, permitido instalar sólidas bases en San [sic] Catalina, Providencia y San Andrés y finalmente alcanzar el anhelado comercio del Pacífico", una ambición que abrazaba la intención de dominar ambos mares y dilatar su imperio hasta el centro de las posesiones americanas españolas (AHNM, SD, Colecciones, 32, n. ${ }^{\circ}$ 36, ff. 50-52).

Con el interés de establecerse en medio de la América española, los ingleses movieron sus armadas, tropas y colonos de la Florida hacia las bocas del Toro y las costas aledañas, en lo que contaban con el apoyo de los mosquitos, pero en medio de todas estas circunstancias, decía Caballero y Góngora: "abría yo una mina que arruinaría sus proyectos”. Los británicos perseguían dos objetivos con la invasión de América Central: de un lado, interrumpir, por medio de establecimientos, el dominio español en todo el continente y cortar la comunicación empresas cortadoras de palo de Campeche exportó a Nueva York, Rhode Island, Jamaica, Londres, Bristol, Holanda y Carolina del Sur, actividad que se extendió hasta comienzos del siglo xx. 
por tierra entre el norte y el sur de América. Y del otro lado, extender su comercio, usufructuando las producciones de los habitantes del país e introducirlo a las "provincias confinantes". Con el apoyo de los indígenas, "todo el poder de España no hubiese podido excluirlos” (AHNM, sD, Colecciones, 32, n. 36, ff. 55).

Hodgson, apresado en 1783 y movido por un resentimiento contra algunas autoridades de su nación, como también por el interés de obtener beneficios al servicio de los Borbones, puso en manos españolas una valiosa información que alertó a la Corona de los riesgos de perder América Central, proponiendo al tiempo una solución al conflicto mosquito. Analizada la información y comprobada la sinceridad y los beneficios de la propuesta, el virrey autorizó, "no sin recorrer un camino lleno de vicisitudes, tratar con los pueblos mosquitos bajo la premisa de que el vasallaje hacia España era ahora preferible al del Inglaterra". No había duda, Góngora consideraba al coronel hombre de formación sólida, emprendedor obstinado y ambicioso en interés y gloria, y buen conocedor de la región en disputa. Los motivos que justificaron su actuar se centraban en las ventajas que ofrecía ese territorio, así como en evitar los grandes perjuicios económicos que resultaban de la casi total posesión del litoral centroamericano por los ingleses (AHNM, SD, Colecciones, 32, n. ${ }^{\circ}$ 36, ff. 55-57).

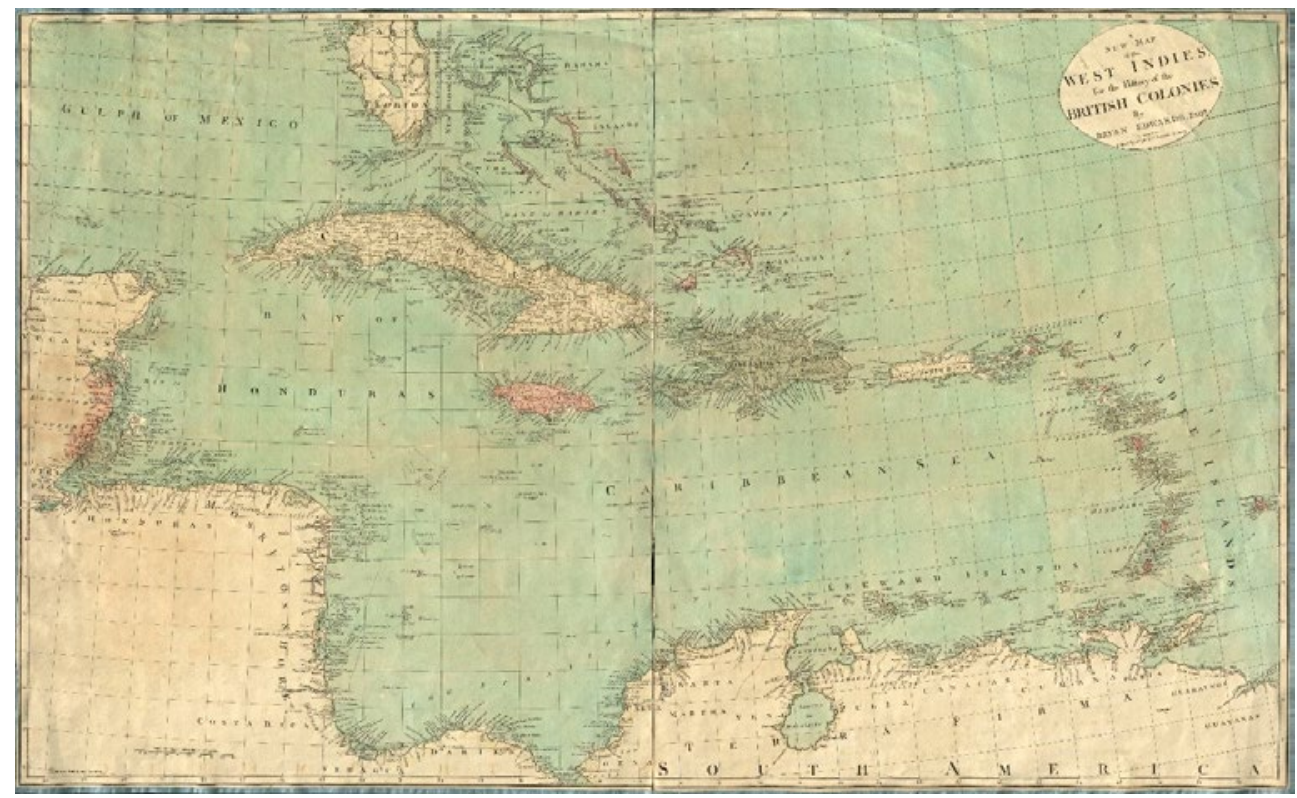

ar FIGURA 3.

New map of the West Indies for the History of the British Colonies, 1793

Fuente: BVDE, MPCN, I4-A-I2, I793. 


\section{Las proposiciones de Hodgson para sujetar a los mosquitos}

Hodgson conocía las dificultades históricas que enfrentaron los españoles para controlar a los pueblos mosquitos, por eso, el primer punto fue la necesidad de conquistar o conciliar con los indígenas asentados entre Nicaragua y Trujillo (Payne). La primera acción sería enviar misioneros a residir entre ellos y predicar el catolicismo, y la segunda, estorbar a los extranjeros con quienes comerciaban. Un punto importante era conciliar con los pueblos del Darién y definir con claridad la línea que permitía a los ingleses extraer el palo de Campeche, pero esto solo podía ser ejecutado por él, que conocía el país y sus gentes (AGS, $S G U$, 6945, I, f. 325).

Proponía erigir un gobierno que, probablemente por la naturaleza administrativa española, debería estar sujeto a Guatemala, aunque por su lejanía expresaba la conveniencia de extender un gobierno desde Nicaragua hasta Trujillo, y en la costa, desde la bahía de la Candelaria hasta Bacalar, incluyendo el comando de Omoa y el de todas las pequeñas islas hasta Providencia y San Andrés (AGS, SGU, 6945, I, f. 326).

Para ejecutar el plan solicitaba una fragata, y como "era hombre de mar y tal vez el mejor piloto de esa costa”, ser nombrado capitán. Pedía una flotilla auxiliar con una lancha cubierta, dos botes armados, canoas, quinientos hombres y el grado de coronel. Por último, solicitaba 8 ooo pesos fuertes para obsequiar a los indígenas. Los cinco o seis sacerdotes enviados al territorio quedarían sujetos a él en el plano temporal (AGS, $S G U, 6945$, I, ff. 327-328). Si fuese necesario levantar fuertes, se ofrecía como ingeniero para reducir costos, pero solicitaba un aporte para pagar a dos oficiales de apoyo.

Personalmente, solicitaba título de brigadier "con todos los honores y proporciones” del ejército de España y, además, conservar su grado inglés. El acuerdo le permitiría volver a su patria a los cinco años y llevar los útiles personales libre de derechos. También solicitaba oficiales subalternos como ayudantes. Por último, la tierra tomada en el país de los mosquitos y refrendada en Jamaica debía concedérsele a él y sus herederos por leyes españolas (AGS, $S G U, 6945$, I, f. 332). En cuanto a los 150 esclavizados que poseía en la costa y que no podía vender, con el peligro de perderlos si no trabajaban, pedía permiso para transportarlos libre de derechos y emplearlos en el desmonte de palos y raíces del país.

Para tomar la decisión meditaría en Jamaica y viajaría a Bluesfield con el ánimo de tantear a los mosquitos. Después, solicitaba volver a Cartagena para 
ver al virrey o, al menos, poder enviar sus cartas a Portobelo, distante cien leguas de Bluesfield, donde se había establecido con su familia. Todo cambió tras el Acuerdo de París, pues sus posesiones materiales se afectaron, los ingleses solo podían estar entre el río Walix y la desembocadura del río Hondo, y los demás territorios debían ser abandonados en el término de ocho meses, tras la ratificación del tratado.

José Fuertes traducía los papeles y expresaba al virrey que sería bueno mantener la negociación con Hodgson, pues resultaba de utilidad poseer este espacio del Caribe para perjudicar el comercio de Jamaica, que anualmente obtenía 400000 libras de zarzaparrilla y 14000 de carey, añil, cacao, algodón, otros palos y muchas medicinas, y eso que los colonos ingleses no superaban los I50. Incluir el Darién y pensar en compañías comerciales en ambas partes era lo mejor, porque "sin conquistar y poblar de modo útil" y dar estímulos para hacer apetecible aquellas costas sería difícil. De esta forma, se pondría en acción un proyecto político que fortalecería a la declinante plaza comercial de Cartagena ${ }^{4}$ :

Cuando hablo de esto, me acuerdo de lo que puede ser esta provincia bien unida por la franqueza del comercio con el Chocó, Panamá, Darién, Nicaragua, y costa de los mosquitos, reviviría a Cartagena y llegaría el caso de que pudiéramos ya enviar dinero a España desde aquí [...] Nada siento más que el estar lejos de VM para hablar de estos asuntos y del modo de hacer florecer el comercio en este Nuevo Reino que siempre ha sido tan miserable por falta de estímulos. (AGS, $S G U, 6945$, I, f. 36I)

\section{Caballero y Góngora insiste en la negociación}

La propuesta fue enviada a Madrid y el rey la aprobó, pero recordando que no convenía admitirlo al servicio de España (ags, $S G U, 6945$, I, f. 357). Ante la fría y evasiva respuesta del virrey en febrero 1784 , Hodgson solicitó viajar a España

Aunque Cartagena a finales del siglo XviII mostró signos de recuperación económica como consecuencia del impulso de los ingresos producto del situado, tal recuperación no estuvo a la altura de las economías de otros puertos caribeños. Su población a finales del siglo XVIII era de 13600 habitantes, a pesar de albergar el segundo apostadero militar de la armada más importante de la región. En comparación, Veracruz alcanzaba en las mismas fechas los 16000 habitantes; Kingston, 20000 habitantes; Santo Domingo, 25000 habitantes; y La Habana, con la misma condición militar, superaba los 76000 . 
a la corte. En agosto el virrey respondió que lo recibiría en Cartagena para acordar cómo "atacar y extinguir o reducir" a los indígenas del Darién y Calidonia, quienes a fines de 1782 "exterminaron a cuchillo a más cuatrocientos españoles" (AGS, $S G U, 6945$, I, f. 39I), y un año después a otros trescientos en San Jerónimo de Buenavista, junto a Lorica (AGS, $S G U, 6945$, I, f. 722). Caballero y Góngora mantenía recelos y solo le ofrecía sueldo de coronel y permiso para el asiento de su familia en San Andrés y en Santa Catalina (AGs, SGU, 6945, I, ff. 405-407).

Los oficiales españoles pensaban que la propuesta reflejaba el resentimiento hacia su corte, y "que ello lo estimulaba a buscar un mejor premio en nosotros", aunque también consideraban que sus servicios permitirían "poblar y beneficiar aquellas costas" y, sobre todo, enfrentar el peligro en Calidonia (AGS, $S G U, 6945$, I, ff. 432-434). Hodgson enfatizaba en poblar las islas, pues abandonadas habían sido ocupadas por "algunas miserables familias que se mantenían del corte de madera y la pesca de tortuga”. Algunos sostenían que Santa Catalina y Providencia podían ser de utilidad, lugares donde el inglés había establecido sus intereses familiares y acrecentado su fortuna e influencia. Para evitar la expulsión usó un inteligente argumento: si bien, de parte paterna disponía de la protección inglesa, también debía confiarse a Su Majestad católica por haber nacido él, su madre y sus abuelos en sus dominios. La obligación de retirarse junto a los ingleses asentados en Honduras lo hacía apelar a que esa era "la peor raza de entre las más malas y que no podía tolerarlo porque eso sería despreciar y vulnerar su noble educación”. Por ello, se consideraba legitimado para ponerse en manos de los espańoles y junto a su familia jurar fidelidad a la Corona (Román y Vidal).

Sus argumentos apelaban a que lo incautado resumía servicios e informes de sus ańos en la Mosquitia y demostraba su capacidad para llevar a cabo su propuesta. En cuanto a la acusación de la pérdida de fidelidad a Inglaterra, sostenía que no necesitaba más prueba que el edicto "calumnioso" expedido en su contra en Jamaica. En marzo insistía, mediante una carta (AGS, $S G U, 6945$, I, f. 478), en ser recibido para explicar que deseaba pasarse "de corazón" al lado español y poder quedarse en aquellas costas (AGs, $S G U$, 6945, I, f. 44I). Solicitaba no ser detenido, satisfacción de los gastos del viaje y un sueldo "digno a su clase” hasta regresar. El virrey consideró que recibir al coronel sería útil para la ejecución del tratado, para expulsar a los ingleses e iniciar acciones contra mosquitos, zambos y calidonios, privando a los ingleses de cualquier proyecto sobre el istmo y sus costas. Contestó aceptando los términos pretendidos (AGS, $S G U, 6945$, I, f. 429). En septiembre de 1784, con cautela y sagacidad, aprobó las condiciones para iniciar la "conferencia". 
Desde Cartagena, en secreto, partió una goleta de inteligencia con instrucciones de entregar los pliegos al coronel Hodgson y evitar que fuera interceptado por el enemigo. Navegaron a Jamaica, al amparo de la bandera de comercio española, y llegaron en seis días para averiguar el paradero del coronel. En Port Royal marineros diestros en el inglés compraron cerveza, ron y otras bagatelas y lograron establecer su paradero. Levaron anclas rumbo a Bluesfield, donde llegaron una semana más tarde. Una vez allí, se entregaron los pliegos. La respuesta llegó un día más tarde y la goleta partió hacia Cartagena. Los oficiales informaron del armamento de Hodgson (cuatro cañones y un almacén de pólvora) y a su llegada vendieron el aguardiente, sin poder decir su origen por la naturaleza de la operación. No se hizo aduana hasta autorización oficial y con lo obtenido se financió la discreta operación (AGS, $S G U$, 6945, I, ff. 536-537).

La información del plan inglés de apoderarse de Nicaragua fue remitida a la Audiencia de Guatemala para que tomara las medidas necesarias dado el caso (AGS, SGU, 6945, I, f. 546). Tras el informe del virrey, Madrid permitió enviar el salvoconducto, pero insistiendo en tener precaución y desconfianza, pues Hodgson había dilatado demasiado la negociación (AGS, $S G U, 6945$, I, f. 553).

\section{Hodgson en Cartagena, la negociación y la propuesta}

El virrey atrajo a Hodgson y en abril de 1785 su bergantín fondeó en Bocachica, donde se aseguró el buque y el coronel tomó tierra. Lo recibió José Fuertes, interprete en esta negociación, quien lo condujo ante el virrey. Al encontrarse, manifestó que su honor lo llevaría a cumplir su propuesta, pero exigía el grado de brigadier. El virrey explicó que un ascenso "no se conseguía con prontitud y menos sin resultados", pero si aceptaba el grado de coronel, el trato sería inmediato. Hodgson, debido a asuntos personales, solicitó pasar por Jamaica y Bluesfield, lo que el virrey aceptó, y le otorgó un salvoconducto y la promesa de proteger a su familia en las islas.

El inglés prometió volver en tres o cuatro meses. Caballero y Góngora entendía la utilidad de que se quedase en Bluesfield para dividir a los naturales. Aunque desconfiaba de las razones del inglés para pasarse a su servicio, sabía que uno de los principios que lo arrastraban a tal decisión eran sus establecimientos de cortes de caoba, que le importaban al año más de 60 ooo pesos (AGS, $S G U, 6945$, I, ff. 562-563). Tras estudiar la documentación era obvio que conocía 
la geografía de las costas hasta el Atrato, así como el río San Juan y el lago de Nicaragua. Su experiencia lo hacía poseer, además de las ideas necesarias para comerciar en esos territorios, pues conocía sus dificultades, recursos y las necesidades para cualquier empresa comercial. Entendía las costumbres de los pueblos mosquitos, sus artes de guerra, sus montes impenetrables, los pantanos y, lo más valioso, cómo conservar un ejército sin ser devorado por las epidemias: "Que este coronel poseído del espíritu de comerciantes de su nación y es uno de los oficiales que puede hacer negocio por el río San Juan impunemente con el país interior" (AGS, $S G U, 26$ de julio de 1783 , f. 578). En definitiva, estaba convencido de que su conocimiento sería útil y, sobre todo, al depauperado y dependiente Virreinato del Nuevo Reino de Granada, que podría resurgir si "se pudiese poner en movimiento la fértil provincia de Nicaragua” (AGS, $S G U, 6945$, I, f. 583).

\section{La ejecución de la propuesta}

Hodgson era consciente de que sus establecimientos en Bluesfield y los cayos de mangles estaban en riesgo por su fidelidad a España, a ello había que sumar su presencia en la costa de Veragua y en la isla de Santa Catalina, por lo que exigió que la licencia de sus acuerdos fuese extensiva a sus herederos (AGS, $S G U$, 6945, I, f. 6o8).

Los mosquitos estaban divididos en dos castas, los indios nativos y los zambos, por lo que sería de gran utilidad introducir entre ellos la discordia, y también era urgente expulsar a los ingleses, porque ello permitía que indígenas y zambos tuviesen contacto con Jamaica. Una recompensa para que abandonasen las costas podría ser la licencia para renovar el corte de palo en Honduras. Era indispensable asimismo suministrar guardacostas y barcos de guerra, corsos que pusieran en riesgo cualquier presencia, como también quitar a los mosquitos su propio territorio y ocupar toda la costa desde Chagres para proteger la pesca de carey y a los indios cristianos, cuyos productos vendían los mosquitos a Jamaica, pretensión que no era difícil de alcanzar, considerando que se trataba de un comercio de barcos pequeños mal equipados.

Hodgson también proponía construir fuertes de menor tamaño para dificultar cualquier actividad, y cerraba con dos ideas: armar a los indígenas cristianizados y tener un barco siempre presente. Solicitaba comprar cincuenta o sesenta esclavizados en Jamaica para ejecutar el plan. No se atrevía a hacer consideraciones tan claras para la costa del Darién porque, si bien, las navegaba 
y conocía a algunos jefes e incluso intérpretes, pensaba que había personas con más conocimiento (AGS, $S G U, 6945$, I, ff. 618-625).

Hodgson se puso a disposición del rey e insistió en la licencia para que su familia, criados y esclavizados vivieran en Bluesfield e Islas de Mangle y, también, por si fuese necesario, trasladarse a las islas de San Andrés, Santa Catalina y las costas de Veragua. Exigía seguridad para que sus barcos tuvieran licencia. La propuesta llegó vía Cartago de mano del teniente del valle de Matina, quien envió los pliegos a Cartagena.

Tras su viaje a Londres en 1785 lamentaba dos cosas: por un lado, el maltrato recibido y el manejo "vergonzoso" que Inglaterra hizo del cumplimiento del tratado, y por otro, el deseo público en Jamaica, de matarlo a él y a sus esclavizados, por su acercamiento a los españoles. Insistió en la necesidad del guardacostas para "agasajar" a los indígenas e inclinarlos a los españoles. Había que eliminar lo que denominaba "una casta de blancos compuestos de ingleses refugiados de América del Norte y de facinerosos y prófugos de Jamaica que estorbaban sus diligencias, y que tras la cesión del rey Jorge, sin dilación debían abandonar la Mosquitia" (AGS, $S G U$, 6945, I, f. 754). Finalmente, el tiempo se dilataba y sus argumentos y retrasos aumentaban la desconfianza de Góngora, pero, al mismo tiempo, la no definición del acuerdo llenaba de angustia y ansiedad a Hodgson en su destierro inglés, viéndose abocado a no abandonar la causa de jurar fidelidad a Carlos III.

\section{El triunfo del virrey}

Los recelos, la desconfianza y la paciencia de Caballero y Góngora fructificaron. El intento de retrasar el compromiso se volvió en contra del inglés, la situación se tornó amenazante por el cariz de traición que asumió su proceder. Finalmente, el virrey le escribió recordándole su promesa de volver y esta vez se exigía respuesta categórica, sin ambigüedades ni demoras. Hodgson respondió al fin justificando que no había sido suya la culpa del paso del tiempo, pero que ahora debía aventurarse hasta la "indiscreción" (AGS, $S G U, 6945$, I, f. 82I).

A pesar de la respuesta, la desconfianza seguía patente en ambas partes y la situación se alargó. El gobernador de Matina, presionado para destrabar el asunto, propuso usar las licencias ocasionales que Cartagena otorgaba para enviar géneros a Matina, y, aprovechando esos viajes, mandar a alguien de confianza para presionar al inglés a ratificar el acuerdo. Poco tiempo después 
llegó una carta en la cual explicaba que había estado rodeado de indígenas del Darién y ocupado en tratar de comunicarse vía Matina (AGS, $S G U, 6945$, I, f. 854), asimismo, que durante ese tiempo había sufrido un accidente que lo disminuyó y que había intentado con una piragua dar alcance al bergantín que iba desde Matina a Cartagena, sin lograrlo, y, sobre todo, que existía demasiado peligro para abandonar sus establecimientos.

Finalmente, Góngora actuó y envió a Portobelo al comandante Arguedas y a José Fuertes. Definitivamente, los problemas del Darién y el conocimiento de los nativos que tenía lo hacían un socio demasiado valioso. Las instrucciones ordenaban a los marinos forzarlo a entender el interés español, pero que era necesario ir a Cartagena a prestar juramento de fidelidad a Carlos III. Si no, amenazaban, se verían obligados a evacuarlo de la Mosquitia. El virrey necesitaba la alianza, pues pensaba que los mosquitos le podrían ayudar contra los "darienes"s (AGS, $S G U, 6945$, I, ff. 862-863).

Finalmente, el 28 de febrero de 1787 , el coronel Hodgson, proveniente de Bluesfield, entró al amanecer en el puerto de Cartagena de Indias. Una vez desembarcado fue alojado en casa del virrey. Durante la mañana hubo conversaciones reservadas y comenzaron las negociaciones con sus disculpas por no haber venido desde 1785 , como había prometido. Góngora tomó la iniciativa y expuso las ventajas perdidas con la dilación del acuerdo y que sabía lo que se pensaba de él en Jamaica, y también señaló que le preocupaba su situación, pues se hallaba expuesto y odiado por sus compatriotas. Por ello, le ofrecía protección siempre que hiciese juramento. Convencido de la situación con sus compatriotas y suavemente empujado hacia la bondad del monarca espańol y sus ministros, aceptó e hizo el juramento de fidelidad que autorizaron los jefes militares de la plaza, tres ministros togados y un gran número de personas.

El coronel prometió traer a los jefes mosquitos para jurar fidelidad al rey, un paso de consideración que necesitaba prudencia, pero ahora que los ingleses evacuaban las costas, separados los pueblos mosquitos de sus protectores, pensarían en su propia conservación y aceptarían las manos españolas. El virrey no pudo contener una sonrisa que mostraba su felicidad cuando el coronel inglés, de rodillas, descubierta su cabeza y juntas sus manos, hizo juramento bajo un sol de justicia prometiendo para siempre ser fiel vasallo. Semanas después varios jefes mosquitos repitieron el rito en Cartagena de Indias (AGS, SGU, 6945, I, 
ff. 897-903). Como testimonio de la victoria de Caballero y Góngora quedó, de un lado, el establecimiento de cuatro poblaciones españolas en Black River, Cabo de Gracia, Bluesfield y la desembocadura del río San Juan, y del otro, a finales del 1787 , la autorización para que la familia Hodgson residiera en Bluesfield. Con los ingleses expulsados y los mosquitos del lado español, la caída de los “darienes" era posible. Su proyecto político y de reanimación económica del virreinato sería factible aprovechando la potencialidad de América Central.

\section{Consideraciones finales}

El expediente de Hodgson evidencia, sin lugar a dudas, el proceso de reacomodación imperial vivido en el Caribe occidental en el último cuarto del siglo XVIII. Especialmente, evidencia las frustraciones de los imperios español e inglés en su ambición de lograr un control efectivo sobre los territorios de las costas centroamericanas y una conexión interoceánica que les permitiera fortalecer el comercio del Caribe con el Pacífico. Ambos imperios se esmeraron por impedir los éxitos de su oponente, llevándolo al fracaso una y otra vez, y fue precisamente ello lo que llevó, de un lado, a los acuerdos de paz, y de otro, a implementar estrategias por parte de las armadas, más allá de la confrontación. En este contexto, los marinos, los agentes comerciales y los pueblos nativos desempeñaron un papel preponderante en el complejo juego de intereses que transformó el mapa de la dominación colonial. Tal fue el caso analizado, de Robert Hodgson, quien actuando bajos sus propios intereses supo negociar y actuar más allá de las decisiones metropolitanas (Potthast).

Cabe resaltar que el papel de estos hombres del mar en un Caribe heterogéneo, producto de muchas localizaciones y lugares, formaba una historia conectada que, como sostiene Ana Crespo, supera las ideas nacionalistas historiográficas y permite ver un mayor número de procesos históricos interdependientes y un espejo en miniatura de la globalización (Crespo 577-605). Los barcos reflejaban la idea de un imperio global que presentaba características espaciales que implicaban la ausencia de fronteras permanentes y exclusivas. Hodgson es un ejemplo consistente de estas particularidades en estas franjas porosas de los imperios. Su puesta al servicio de los dos imperios en disputa de la zona lo convierten en un actor privilegiado como marino, militar y agente comercial, y ejemplifica la realidad sobre las identidades y las lealtades ambiguas de los hombres del mar. 
El proceso manifiesta también cómo la articulación de este espacio imperial caribeño y marítimo era muestra de la naturaleza fragmentada y compuesta de la monarquía hispánica con sus diferentes territorios de estatus fronterizos, donde había relaciones interdependientes entre las entidades periféricas. A diferencia de la independencia de un hombre de mar como Hodgson, el proceso ejecutado por Caballero y Góngora fue consultado siempre con Madrid, y la comunicación entre Cartagena y la Audiencia de Guatemala se limitó a la información de procederes, pero no a la toma de decisiones.

Por último, vale destacar el interés por el Caribe occidental que surge desde el Virreinato del Nuevo Reino de Granada. En el marco de estas negociaciones con Hodgson, el virrey no solo doblegó al coronel, sino que también vislumbró, a partir de los acontecimientos, un proyecto político económico para recuperar la declinante economía cartagenera, que había perdido toda su relevancia comercial en comparación con otros puertos y vivía subsidiada de los situados militares. La información comercial inglesa, la navegabilidad de sus ríos y la prodigiosa abundancia y variedad de sus recursos naturales, así como por primera vez la posibilidad de conseguir que los mosquitos reconociesen a los españoles podían permitirle la posibilidad a este puerto caribeño de ampliar el comercio con el Chocó, Panamá, Darién, Nicaragua y la región mosquitia (AGS, $S G U, 6945$, ff. 897-903) ${ }^{6}$.

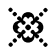

\section{$\begin{array}{llllllllllll}\text { B I } & B & L & I & \mathbf{O} & G & \mathbf{R} & \mathbf{A} & \mathbf{F} & \mathbf{I} & A\end{array}$}

\section{F U E N T ES PR I M A R I S}

Archivo General de Indias (AGI). Guatemala, MP, 333 al 342.

Archivo General de Simancas (AGs).

Secretaría de Guerra $(S G U)$.

Archivo Histórico Nacional de Madrid (AHNM).

Sección Diverso $(S D)$.

6 Vía reservada, ceremonia y actores, Cartagena de Indias, 6 de marzo de 1787. 
Biblioteca Virtual de Defensa en España (BVDE).

Mapas, Planos y Cartas Naúticas (MPCN)

"New Map of the West Indies: For the History of the British Colonies / By Bryan Edwards".

"Plano dela Costa de Mosquitos / nuebamente emmendada, con motivo del destino que tubieron los Buques del mando del Capitan de Navio dn. Pedro de Obregon, en el año de 1787 ”.

\section{I. F U E N T E S S E U N DARIA S}

Appadurai, Arjun. Modernity at Large: Cultural Dimensions of Globalization. Mineapolis: University of Minnesota Press, 1996.

Bernabeu Albert, Salvador, editor. Poblar la inmensidad: sociedades, conflictividad y representaciones en los márgenes del imperio hispánico siglo XV-XIX. Barcelona: Consejo Superior de Investigaciones Científicas (CSIC), 2010.

Bernardini Paolo y Norman Fiering, editores. The Jews and the Expansion of Europe to the West. Nueva York / Oxford: Bergham Book, 200I, DoI: https://doi.org/10.2307/ j.cttix $76 \mathrm{f}_{5 \mathrm{z}}$

Bosch, Juan. De Cristóbal Colón a Fidel Castro. El Caribe frontera imperial. México: Porrúa, 2009.

Cervera, Ana Elvira. "Paisajes liminares: la concepción de la naturaleza en los territorios fronterizos". Perspectiva Geográfica, vol. 24, n. ${ }^{\circ}$ 2, 2019 , pp. I06-I2 4, DOI: https://doi. org/10.19053/01233769.9317

Conover, Carlos. "De los frentes de batalla a los linderos tangibles en el sureste novohispano. La demarcación de los límites de los territorios ampliados de los establecimientos británicos del Walix por la convención de Londres de 1786 ”. Revista História de América, n. ${ }^{\circ} 152,2016$, pp. 9I-I33.

Corvisier, André. Armies and Societies in Europe, 1494-I789. Bloomington / Londres: Indiana University Press, 2002.

Crespo Solana, Ana. "El comercio colonial español de la Carrera de Indias”. Anuario de Estudios Hispanoamericanos, vol. 75, n. ${ }^{\circ}$ 2, 2018, pp. 577-592, DOI: https://doi.org/10.3989/ aeamer.2018.2.07

Dass, Veena y Deborah Poole. "El Estado y sus márgenes. Etnografías comparadas”. Cuadernos de Antropología Social, n. ${ }^{\circ}$ 27, 2008, pp. 19-52.

Dickinson, Harry. Educating the Royal Navy, Eighteenth and Nineteenth, Century Education for Officers. Nueva York: Routledge, 2007. 
Elliot, John H. Empires of the Atlantic World: Britain and Spain in America, I492-1830. New Haven / Londres: Yale University Press, 2007.

Floyd, Troy. The Anglo-Spanish Struggle for Mosquitia. Albuquerque: University of New Mexico Press, 1967.

Fuentes, Nara, compiladora. Rutas embarcaciones y pueblos del mar. Bogotá: Instituto Colombiano de Antropología e Historia, 2018.

---., compiladora. El sujeto en la historia maritima. Bogotá: Instituto Colombiano de Antropología e Historia, 2020.

Gámez, José Dolores. Historia de la costa de los Mosquitos hasta I894. Managua: Taller Nacional, 1939.

García, Claudia. "Hibridación, interacción social y adaptación cultural en la Costa de Mosquitos, siglos XVII y XVIII". Anuario de Estudios Americanos, vol. 59, n. ${ }^{\circ} 2,2002$, pp. 44I-462, DOI: https://doi.org/I0.3989/aeamer.2002.v59.i2.I8I

--.. The Making of the Miskitu People of Nicaragua. The Social Construction of Ethnic Identity. Estocolmo: Almqvist \& Wiksell, 1996.

González-Ripoll, María Dolores. "Idea y representación del Caribe en la cartografía española del siglo XVIII". Contrastes, vol. I2, 200I-2003, pp. 8I-92.

Gould, Elija H. "Entagled Histories, Entagled World. The English-Speaking”. The American Historical Review, vol. I2, n. ${ }^{\circ}$ 3, 2007, pp. 764-786, DoI: https://doi.org/10.1086/ ahr.112.3.764

Griffith Dawson, Frank. “William Pitt's Settlement at Black River on the Mosquito Shore: A Challenge to Spain in Central America, 1732-87”. The Hispanic American Historical Review, vol. 63, n. 4 , 1983, pp. 677-706, DoI: https://doi.org/10.2307/2514901

Hunt, Nadine. "Contraband, Free Ports and British merchants in the Caribbean Worlds, I739-1772". Diacronie. Studio di Storia Contemporanea, vol. I3, n. I, 2013, pp. 2-I I, DoI: https://doi.org/10.4000/diacronie.672

Klooster, Win. “Contraband Trade by Curacao's Jews with Countries of Idolatry I660-1800”. Studia Rosenthaliana, vol. 31, n. ${ }^{\circ}$ I/2, 1997, pp. 58-73.

Marchena Juan y Justo Cuño. Vientos de guerra apogeo y crisis de la Real Armada 1750-I823. Madrid: Editorial Doce Calles, 2018.

Millette, James. Elsistema colonial inglés en Trinidad. La Habana: Casa de las Américas, 1970.

Muñoz Mata, Laura, coordinadora. Mar adentro: espacios y relaciones en la frontera MéxicoCaribe. México: Instituto Mora, 2008. 
Offen, Karl H. "British Logwood Extraction from the Mosquitia". The Hispanic American Historical Review, vol. 80, n. ${ }^{\circ}$ I, 2000, pp. I13-136, DOI: https://doi.org/10.1215/001821688O-I-II3

--.. "The Sambo and Tawira Miskitu: The Colonial Origins and Geography of Miskitu Differentiation in Eastern Nicaragua". Etnohistory, vol. 49, n. 2 , 2002, pp. 319-372, DOI: https://doi.org/10.1215/0014180I-49-2-319

Ortega del Cerro, Pablo. El devenir de la élite naval. Experiencias de los oficiales de la armada en tiempos de cambio (inicios del siglo XVIII, finales del siglo XIX). Madrid: Sílex, 2018.

Paquette, Gabriel. "The Image of Imperial Spain in British Political Thought, 1750I800”. Bulletin of Spanish Studies, vol. 81, n. ${ }^{\circ}$ 2, 2004, pp. 187-2 I 4, DOI: https://doi. org/10.1080/1475382042000206574

Pastor, Rodolfo. Historia de Omoa. Tegucigalpa: Instituto Hondureño de Antropología e Historia, 2008.

Payne, Elizet. El puerto de Truxillo. Un viaje hacia su melancólico abandono. Tegucigalpa: Guaymuras, 2007.

Potthast, Bárbara. "Centroamérica y el contrabando por la costa de Mosquitos en el siglo XVIII”. Mesoamérica, vol. 36, 1999, pp. 499-516.

Prado, Fabricio. “The Fringes of Empire: Recent Scholarships on Colonial Frontiers and Borderland in Latin America”. History Compass, vol. Iо, n. ${ }^{\circ}$, 2012, pp. 318-333, DOI: https://doi.org/IO.IIII/j.I 478-0542.20I2.00837.x

Puig, Miguel Ángel. Las expediciones cientificas durante el siglo XVIII. Madrid: Akal, I999.

Reichert, Rafal. "El contrabando y sus redes en la Capitanía General de Guatemala, siglo XVIII. Una aproximación al tema". Entre lo legal, lo ilicito y lo clandestino, prácticas comerciales y navegación en el Gran Caribe, siglos XVII alXIX, editado por Johanna Von Grafenstein, Rafael Reichert y Julio César Rodríguez Treviño. México: Instituto de Investigaciones Dr. José María Luis Mora, 2019, pp. 193-213.

---. Sobre las olas de un mar plateado. La politica defensiva española y el financiamiento militar novohispano en la región del Gran Caribe, I598-I700. Mérida: Universidad Nacional Autónoma de México, 2013.

Román, Raúly Antonino Vidal. "Imperialismo y poder a finales del siglo XVIII. Las disputas en el interior del imperio español por el control de la costa Misquita y el Archipiélago de San Andrés y Providencia”. Memorias, historias y olvidos. Colonialismo, sociedady politica en San Andrés y Providencia, editado por Raúl Román y Antonino Vidal, San Andrés Islas: Universidad Nacional de Colombia, 2019, pp. 23-44. 
Rupert, Linda M. “Curacao: ¿entrepot holandés o puerto caribeño?”. El Golfo-Caribe y sus puertos, I600-I850, tomo I, editado por Johanna Von Grafenstein. México: Instituto Mora, 2006, pp. 9I-I26.

Santana Pérez, Juan M. y José A. Sánchez Suárez. "Repoblación de costa de mosquitos en el último cuarto del siglo XVIII". Revista de Indias, vol. 241, 2007, pp. 695-712, DOI: https://doi.org/ro.3989/revindias.2007.i241.628

Shuman Sorsby, Willian. “The Bristish Supertintendency of the Mosquito Shore”. Tesis, Universidad de Londres, Departamento de Historia, Londres, 1969.

Shrimptom, Margaret. "Forgotten Populations in Belize's Literary Landscape: Dismantling the National Narrative From the Borders”. Caribbean Studies, vol. 48, n. ${ }^{\circ}$, 2020 , pp. 7-39, DOI: https://doi.org/IO.1353/crb.2020.0018

Solano, Sergio Paolo. "Artesanos, jornaleros y formas concentradas de trabajo: el Apostadero de la Marina de Cartagena de Indias (Nuevo Reino de Granada) en el tránsito entre los siglos XVIII y XIX”. Theomai, vol. 31, 2015, pp. 79-105.

Solórzano Fonseca, Juan Carlos. "Centroamérica en el siglo XVIII: un intento de explicación económica y social”. Estudios Sociales Centroamericanos, vol. II, pp. II-22, 1992.

Valencia, Fernanda. Visitantes furtivos en Mérida, 1765 construcción y reproducción de visiones inglesas sobre Yucatán. Mérida: UNAM, $202 \mathrm{I}$.

Vidal, Antonino y Raúl Román. "De vasallos británicos a súbditos españoles. Los márgenes borrosos en el Caribe occidental a finales del siglo XVIII y principios del siglo XIX". Temas Americanistas, n. ${ }^{\circ}$ 40, 2018, pp. I6I-I87, DOI: http://dx.doi.org/I0.12795/TemasAmericanistas 